\title{
Are there jobs in academic pulmonary medicine in Canada? A resident's view of the future
}

\author{
JAE YANG MD FRCPC, CHARLES K CHAN MD FRCPC FCCP FACP \\ Division of Respiratory Medicine, the Department of Medicine, the Wellesley and \\ the Toronto Hospitals, University of Toronto, Toronto, Ontario
}

J YANG, CK CHAN. Are there jobs in academic pulmonary medicine in Canada? A resident's view of the future. Can Respir J 1995;2(4):207-209.

A survey of all Canadian academic institutions with an adult pulmonary training program was undertaken in 1992 to investigate the number of positions in pulmonary medicine that would be available up to 1997. The positions were divided into clinician scientist ( $75 \%$ research) and clinician teacher ( $75 \%$ clinical) categories. Inquiry into specific areas of interests and prerequisite training requirements were made. Ten of 14 centres responded; 35 to 44 positions were identified, 22 to 27 for clinician scientists with at least two to four years' research training after completion of a clinical pulmonary fellowship. For the remaining 13 to 17 clinician teacher positions, the requirement was for two to three years of additional clinical training beyond the clinical pulmonary fellowship. Some centres did not specify whether available positions were in the clinician scientist or in the clinician teacher group. The results of the survey suggest that there are jobs available in academic pulmonary medicine but that they are mainly in the basic research area, requiring at least an $\mathrm{MSc}$, and preferably a $\mathrm{PhD}$ or equivalent research training. A questionnaire is included in an attempt to obtain information about other opportunities in both academic and community hospitals.

Key Words: Clinician scientists, Clinician teachers, Employment, Pulmonary medicine, Questionnaires:

\section{Y-a-t-il des emplois en pneumologie dans le réseau universitaire canadien ? Portrait de l'avenir dressé par un résident}

RÉSUMÉ : Une enquête auprès de toutes les universités canadiennes offrant un programme de formation en pneumologic adulte a débuté en 1992 pour déterminer combien de postes seraient offerts en pneumologie jusqu'en 1997. Ces postes ont ćté divisés en deux catégories, chercheur-clinicien $(75 \%$ pour la recherche) et professeur-clinicien (75\% pour la clinique). Le questionnaire portait notamment sur les centres spécifiques d'intérêt et sur les qualifications exigées. Dix centres sur 14 ont répondu; 35 à 44 postes ont été identifiés, 22 à 27 étaicnt des postes de chercheurs-cliniciens ayant au moins deux à quatre annés de formation en recherche après une spécialisation en pneumologie clinique. En ce qui concerne les 13 à 17 postes de professcurscliniciens, les qualifications exigées consistaient en denx à trois années supplémentaires de formation clinique après une spécialisation en pneumologie clinique. Certains centres n'ont pas spécifié si les postes disponibles se trouvaient dans la catćgorie chercheur-clinicien ou professeur-clinicien. Les résultats de l'enquête lais. sent croire que des postes sont disponibles en pneumologie dans le milieu universitaire mais qu'ils sont surtout dans le domaine de la recherche fondamentale, nécessitant au minimum une MSc, et de préférence un $\mathrm{PhD}$ ou une formation en recherche équivalente. On a joint un questionnaire pour tenter d'obtenir des renseignements sur les autres emplois disponibles à la fois dans Ies hôpitaux universitaires et non universitaires 
$\mathrm{T}$ IIS ARTICLE IS BASED ON A COMPILATION OF RISPIONSIS to a survey that was matiled to a number of academic centres across Canada in the summer of 1992. The survey wats conducted to investigate the types of positions that were available to graduating respirologists in sone Canadian aca demic institutions. The principal objectives were to determine what positions were avalable and the training recuirements for them. The results of this totally unvalidated survey are interesting and perhaps helpful for trainees in respiatory training programs across Canadat. Furthermore, the results ma encourage dialogue between laculty and trainees in terms of realistic expectations from both parties in filling these academic positions.

\section{METHODS}

A questionnaire wats mailed to the heads of pulmonary divisions at 14 academic institutions across Canada. These sites were chosen because they were listed as pulmonary fellowship training sites in the American Thoracic Society Registry in 1902(1).

Specific inquiry was made regarding the number of academic positions that might be available up 10 1997. The respondents were asked to classify these positions into cattegories: clinician scientist (CS), defined as all least 75\% time committed towards research; and clinician tcacher (CT), defined as 75\% of time committed towards clinical activities and teaching. Specific requests addressed the type of taining, number of years of additional rescarch/clinical training required, and the prerequisite skills and specific needs.

\section{RESULTS}

From the 14 sites contacted (Table 1), 10 completed questionaires were returned over a period of approximately 15 months. The last responsc was received in September 1993.

Overall, 35 to 44 positions were projected to be available at the 10 academic centres between 1992 and 1997 . The majority, 22 to 27 of these positions, were designated CS positions, and of these, at least 10 were for cellular/molecular biolo- gists. In terms of specific training requirements, the expectations were somewhat variable anong eentres. The minimum perceived requirement to qualify a cellular/molecular biologist for a position in the CS track wats two to three years of rescarch training. The highest expectation in the same caltegory was four to live years, or a PhD equivalent at some centres. Another four of the CS positions were designated for clinical epidemiologists, with a traning requirement of ats little as one to two years and as high as two to three years or MSc equivalent. The remaining cight CS positions were for a wide spectrum of research, encompassing physiology. sleep, oncology and other fields, with an expectation of at least two additional years of reseatch training.

OI the CT positions, four of 10 were for experts in sleep. two for transplantation, two for intensive care-related work and two for laser endoscopy and home ventilation. The general training requirement was about two to three years of additional clinical/laboratory training. It is important to note that not all centres specified how many positions there were in each of the CS or CT tracks. Also, some centres appeared to be flexible, as they did not specily the type of special expertise required.

\section{DISCUSSION}

The limitation of this questionnaire was that it covered only at small portion of what maly be actually available. There are clearly more than 14 acudemic centres across Canada: the requirements at centres that do not ofler pulmonary fellowship traning programs maty be similar to those that responded, but they may be quite different. A suggestion that arises from this uncertainty is for an organization such as the Canadian Thoracic Socicty to keep a central registry of academic centres, which would be updated regularly and contain information on the avalability. type of positions and the training expectations for potential applicants.

Given the limitations of the survey, the conclusions based on the available evidence are that there seem to be ample job opportunitics in acadenic institutions for trained pulmonolo-

\section{TABLE 1}

Academic positions in 10 centres across Canada, 1992-1997

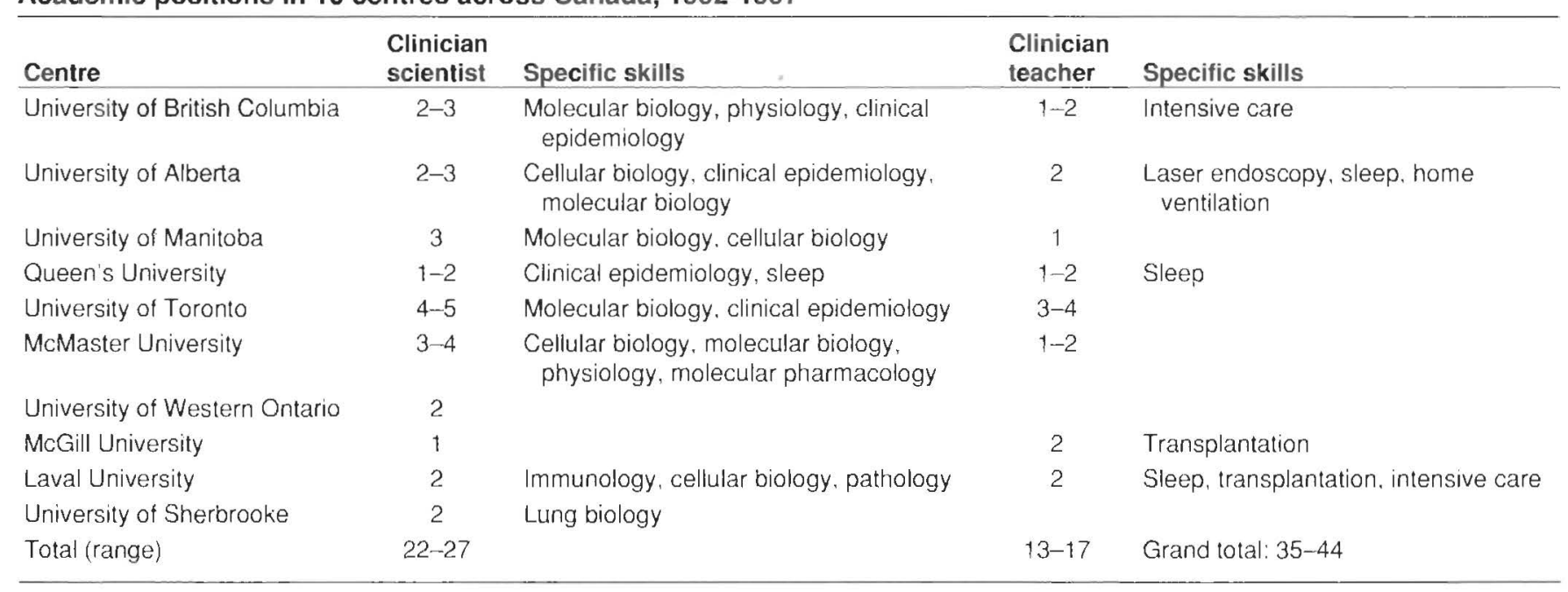


gists, with a great demand for researchers. On the other hand, trainees who have acyuired special clinica! and laboratory skills (Table 1) are also in demand.

We were surprised by the variability among the centres in the prerequisites or type of training and preparation required. Two or three years of training in cellular/molecular biology is probably inadequate to prepare someone as an independent investigator in this field. However, after two to three years of research training, someone who is to be taken into a strong and well established research program may be nurtured in the subsequent years as a junior investigator on faculty. Four to five years of research training will probably provide a much stronger research foundation and allow an individual to become an independent investigator. In the arcit of clinical epidemiology, a minimum of two years is the expectation at most sites. That period of time is generally sufficicnt to allow the trainee to acquire basic skills and educational requirements. But to put the acquired skills into practice and to have a chance to develop as an independent investigator would also require substantial development beyond an MSc training. Thus, a more realistic research training requirement for such individuals may also be three to four years.

For the CT track, the requirements of the late 1990s seem to be in the area of intensive care, transplantation and laser endoscopy. However, sleep medicine and home ventilation are still in demand at selected sites across Canada. The training requirements and expectations are perhaps more realistic, with a minimum of one year, and the optimal training requirement is probably two years, to establish expertise and to function well as a CT in these fields.

From the perspective of a pulmonary trainee, the prerequivites outlined in Table 1 may be a source of worry for those considering a CS track position. There is no question that somewhere between three to five years of the trainee's time will be devoted to developing skills and expertise in one of these research areas. Once the necessary research training has been completed in a particular ficld, there is generally no guarantee that the 'right' joh will be available at a desirable site. Furthermore, some of the jobs that might become avail- able could be taken by trainees from other centres or from the United States. Even assuming a position is avalitable and highly desirable, there is still no guarantee that this heavy investment of time and the sacrifice of personal earnings during training will result in a successful, independent research career. The facts that become evident from this survey are that it takes a special group of very committed respiratory trainees to go into a CS track, but thit for these dedicated individuals, there is a wide selection ol job opportunilies.

In terms of the CT positions, the results of this survey should be taken in context. Since the survey was targeted at academic centres involved in pulmonary fellowship training, the responses reflect the requirements of tertiary centres and should not be generalized to other centres. We hope to use this article to stimulate further correspondence and perhaps provoke comments from chairs of medicine, chicfs of pulnonary divisions, fellowship training program directors and, last but not least, the future of academic pulmonary medicine, the trainees themselves. Given the permission of space and editorial approval by the Canadian Respiratory. Lomnal. a comprehensive survey of current and future job opportunitics in pulmonary medicine at all the academic centres and community hospitals would be of great benefit to current trainees. Our hope is to use this article as a sounding boarct and as the first step in conducting a survey of available positions and possible future positions in the nontertiary academic and community centres for 1995 to 2000 . This will help estatblish a database for graduating pulmonary trainees and help them find a position that suits their needs and qualifications. Thus. we encourage readers of the Joumal, whether head of pulmonary medicine, chief of medicine or chict of staff, to complete the form and return it by mail or by lix. After six months we will tabulate the results, draw some conclusions and provide an update for the Iournul if the response has been adequate.

\section{REFERENCE}

1. ATS/ALA training programs in adult pulmonary disease and critical care and training programs in pediatric pulmonary disease 1992 edition. Am Rev Respir Dis 1992; I46:1111-2.

\section{Mini-survey of respiratory medicine positions across Canada}

Centre or hospital:

Completed by (name):

Title:

Address:

\section{Telephone:}

Fax:

Do you agree to allow publication of the above information?

$$
\square \text { Yes } \square \text { No }
$$

1. How many positions in pulmonary medicine are currently or will become available at your centre between 1995 and $2000 ?$

\section{Are any special skills or training required for this position?} $\square$ Yes $\square$ No

If yes, please specify:

\section{Any other comments?}

\begin{tabular}{lc}
\hline Please return to: & Dr Charles K Chan \\
& The Toronto Hospital, General Division \\
& 10 Eaton N-220 \\
& Toronto, Ontario M5G 2C4 \\
fax: & $416-971-6427$ \\
e-mail: & j.yang@utoronto.ca
\end{tabular}




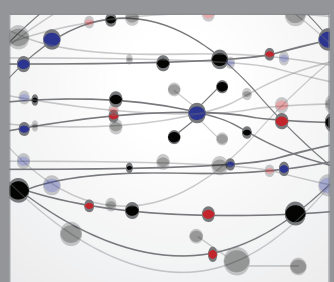

The Scientific World Journal
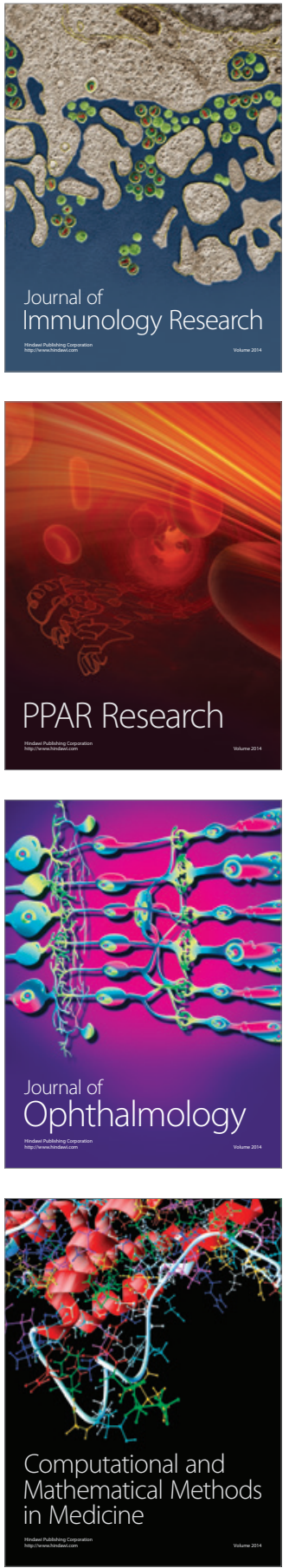

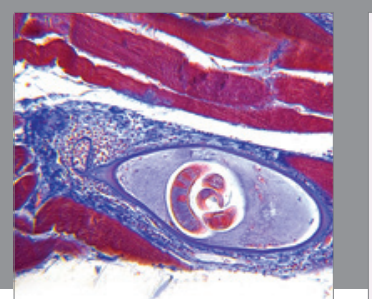

Gastroenterology Research and Practice

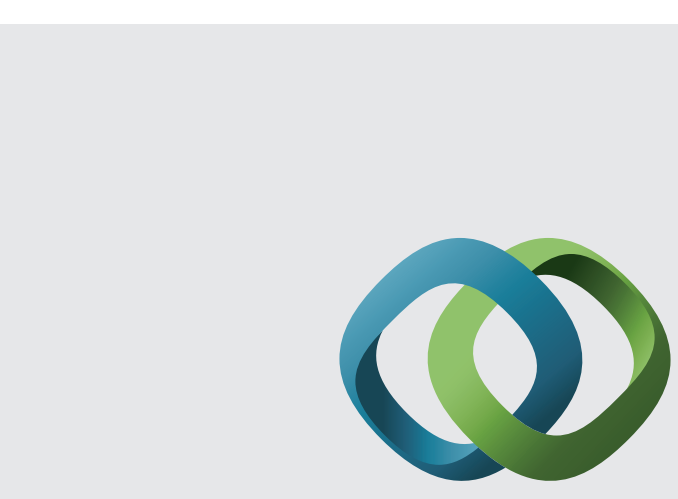

\section{Hindawi}

Submit your manuscripts at

http://www.hindawi.com
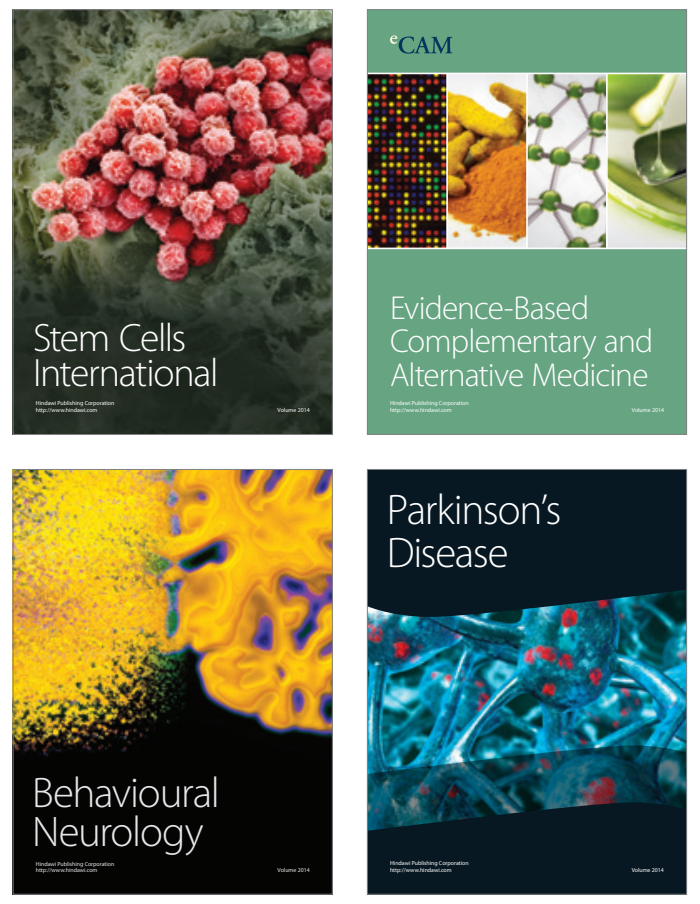
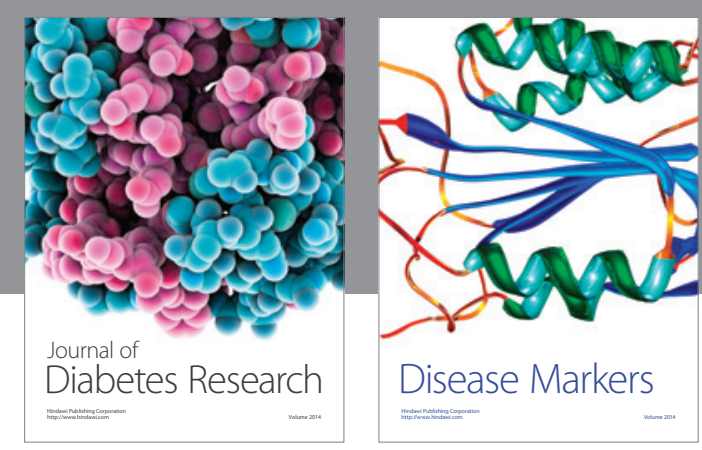

Disease Markers
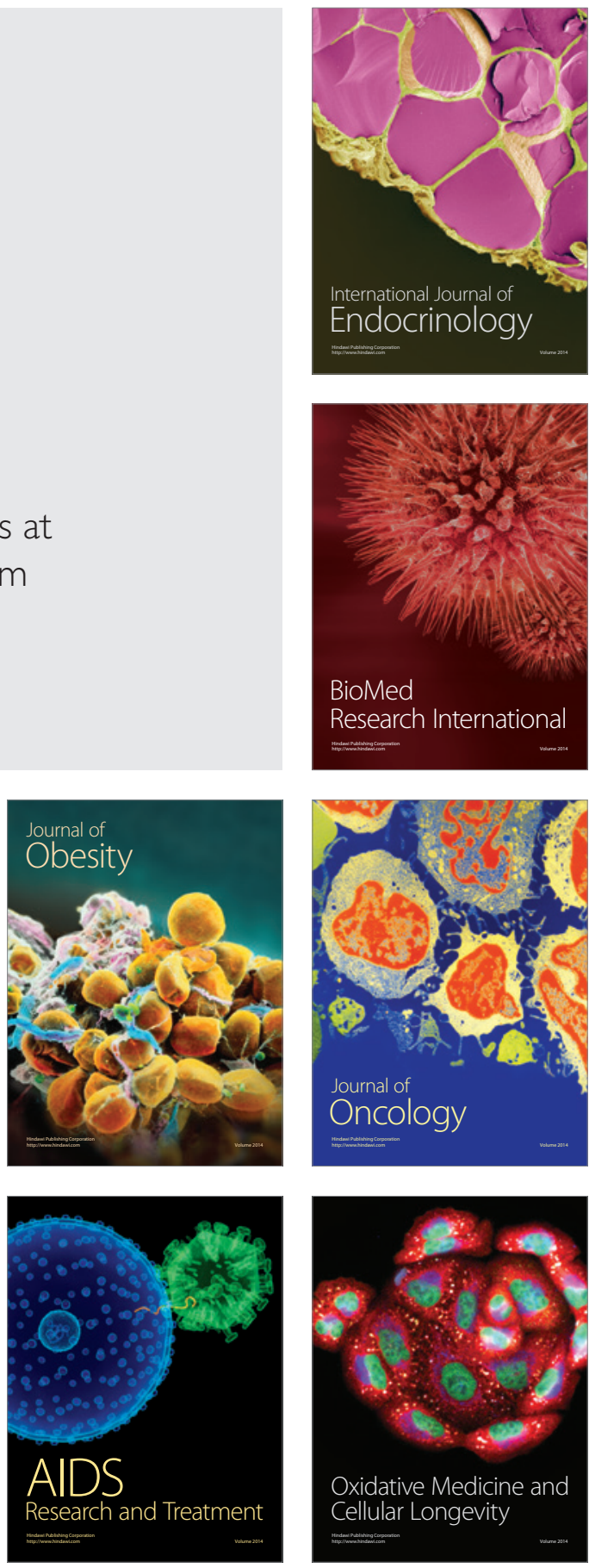